\title{
The Comprehensive Plan of Action (CPA) for Vietnamese Asylum Seekers: Some Reflections ${ }^{1}$
}

\author{
Lawrence Lam
}

Organized by the Jesuit Refugee Service, Asia Pacific division, a meeting on the CPA was aimed at examining the Plan's effectiveness in dealing with the continuing drama of the boat people in Southeast Asian countries. Participants included NGOs (ISS, Save the Children Fund, Family Service International), academics, government representatives, and refugees/asylum seekers in Philippines. Based on observations and informal conversations with NGO representatives and refugees during the conference, the overall impression of the CPA could be summarized as follows:

1. CPA is a complicated plan and a compromising political agreement. The plan is designed to balance the interest of the various parties; first and foremost, to prevent countries of first asylum from carrying out their threat to do away with their asylum policy; to sustain UNHCR's supposedly protective role; and to maintain the interest of resettlement countries (e.g. other countries did the first screening for them; they do not have to spend as many resources in selecting; or as in the case of the U.S., fewer numbers have to be screened);

2. It is heralded and celebrated as a success to prevent clandestine departures. With the European Community and other countries providing economic assistance to Vietnam and with the implementation of repatriation-voluntary repatriation has become strangely silent in favour of an orderly return

This article is based on the Colloquium, organized by the Jesuit Refugee Service, Quezon City, Philippines, October 25 to 28, 1992. Lawrence Lam is a professor of sociology and an associate director at CRS, York University . program-the last chapter of boat people could be written. This would leave UNHCR free to deal with more urgent and pressing refugee problems somewhere else; and

3. The interest, safety and dignity of the asylum seekers have not entered into the equation. It is not a fair and just program for the asylum seekers.

For the countries of first asylum, the underlying assumptions for the implementation of this plan are:

1. It is assumed that over the years, the characteristics of the new arrivals from Vietnam have changed drastically. They are not perceived as real refugees but merely as economic migrants. There cannot be an uninterrupted exodus of genuine refugees from Vietnam because after so many years, conditions in Vietnam should have improved. Therefore, many asylum seekers are simply taking the advantage and opportunity to seek a better life in the West. They are abusing the asylum policy. As such, the plan is designed, in the name of protecting the integrity of the system, to weed out those abusers; and

2. The countries of first asylum have been overburdened by the boat people for too long, and unless a concerted action is taken, there will be no end to the flow of refugees. These countries reasoned that with no guarantee of resettlement elsewhere, they will be left with the boat people forever. Hence, countries of first asylum need to stop being so generous toward the boat people and need to scrap their current asylum policy.

Furthermore, UNHCR and the interested governments are determined:

1. To deter clandestine departures from Vietnam;
2. To gain the agreement of countries of first asylum to maintain this policy;

3. To implement the screening process to determine who is a genuine refugee;

4. To give protection to the genuine refugees, with possible opportunity for resettlement (though not guaranteed); and

5. To implement measures to encourage voluntary repatriation of rejected refugees.

Does the implementation of the screening process fulfil its mandate to protect refugees? Many speakers noted that the processes, in reality, fail to protect refugees. It is easy to determine, based on an extremely narrow interpretation, and more frequently, due to misapplication of the criteria of the UN Convention on the Status of Refugees and 1967 Protocol, that a genuine refugee is not a refugee in need of protection.

Although the CPA does indeed calls for a broad interpretation of the Convention in light of the other relevant international human rights documents-for example, the Universal Declaration of Human Rights, 1948, and in the context of humanitarian spirit-CPA has been used to justify subsequent repatriation of so-called nonrefugees, voluntary or otherwise. Further, the U.K. and Vietnam governments entered into an agreement in 1991 to institute what they called an orderly return program for nonrefugees.

During the conference, Jim Hathaway pointed out that there are two shortcomings in the determination process:

i. consistency in the criteria applied; and

ii. consistency in decision making, including the decision made in the review and appeal. 
Among the first asylum countries, we have seen acceptance as high as 47 percent (Malaysia) and 43 percent (Philippines). However, I was told by participants that Malaysia has been diplomatically cautioned about its high acceptance rate. In the case of Philippines, corruption and bribery have contributed to their high rate. For example, asylum seekers who have relatives already resettled in the West and who have received remittance are more likely to get a positive decision on their claim than those who do not. In Hong Kong, the acceptance rate is around 12 percent because political persecution may be arbitrarily interpreted as merely economic deprivation. This interpretation fails to take into account socioeconomic marginalization which, when systematically carried out by government, is a violation of basic human rights and may legitimately constitute persecution. In one case, among others, a female applicant was stigmatized by her husband's political activities and was consequently denied a family work permit, assigned to unpaid forced labour, and evicted from her home. The Hong Kong Review Board denied that the harm she had experienced was the result of an imputed political opinion or her membership in a particular social group-family. Her experience was characterised as:

not demonstrably punitive and excessive, the period of forced labour were.... with meals, which helped feed her children, as the commune could not give her a proper job due to her husband's offence, she experienced inhumane treatment indeed, but normal practice in a communist country.

\section{Another case in Philippines: \\ while it is true that the couple is re- stricted - though they experienced several years of politically inspired imprisonment, there is no serious problem encountered by them physi- cally, mentally or morally. The only cause for the escape is to obtain bet- ter living in a free world.}

Not only do the common mistakes in misapplying the criteria of the Con- vention exist, there are many traps for the claimants. Arthur Helton noted that often, the claimant is not allowed to elaborate, and must give only yes or no answers. In particular, when questioned about the reasons for leaving, if the claimant answered that he "couldn't make a living," as in the aforementioned cases, he would then be judged as "economically motivated." There is no opportunity for clarification. Hence, asylum seekers were forced to copy other successful claims.

Other issues raised regarding the inadequacies of the CPA-screening included:

1. benefit of doubt not given to claimants;

2. lack of preparation for the screening and pertinent information made available to asylum seekers, including lack of legal counselling;

3. officers not properly trained in the task, usually being the lowest rank in the immigration;

4. lack of monitoring by the UNHCR; ${ }^{2}$ and

5. translation problem and outdated information on condition in Vietnam

Moreover, it was pointed out that the asylum countries are fully aware that even if there were a higher rate of acceptance, not every one of the successful claimants would be accepted for resettlement. They would consequently be creating a burden for themselves. Rather, if more are determined as nonrefugees, chances are that they could return these nonrefugees to Vietnam, in due course. For example, the U.S. does a second screening to select refugees for resettlement while other countries (Canada, Australia) assess these refugees for demonstrated ability to settle successfully.

Regarding the assistance given to the asylum seekers in preparation for the screening, the UNHCR claim that they have tried their best with their limited resources. However, it was pointed out that UNHCR is facing a credibility crisis in the minds of asylum seekers. UNHCR is wearing two hats; protecting and repatriating refu- gees. It was not at all clear to the asylum seekers which role the UNHCR is playing. It has ten field officers but only four could be found working fulltime in the camps to assist the asylum seekers to prepare their cases. Hence, it was not uncommon for the asylum seekers to become familiar with the successful cases and memorize facts which might not be applicable to their own case. The already highly skeptical immigration officers could easily reject such claims. The participant from Hong Kong who is influential in reviewing the cases claimed that these problems are not Hong Kong's making. The review process is 100 percent legally correct because it is careful and thorough. As well, judicial reviews are available to the rejected cases.

While the impact of the psychological trauma of exodus and experience of camp life creates confusion for asylum seekers, no adequate counselling exists for them. Group counselling may take place with some listening to the translation while feeding their babies or attending other chores. Others try to interpret what is being said there within the context of what they had heard from other asylum seekers in the camp.

UNHCR defended the CPA by citing supporting evidence: no more departures (1992 -in Hong Kong, only 11 arrivals), asylum policy maintained, resettlement countries continue selecting refugees for resettlement, and an increasing number of asylum seekers opting for repatriation. They admit that there is always room for improvement, and indeed, UNHCR and the various governments are making continuing efforts to improve the screening process.

For instance, they have trained interpreters from Canada. They also sponsor a program by Jesuit Refugee Services to send lawyers to camps to prepare the cases and persuade governments to use the 'country of origin reports'.

During the entire conference, one would have expected that UNHCR representatives would have seized the opportunity to gather first hand infor- 
mation from the refugees, asylum seekers and rejected claimants. There are many opportunities for interaction, yet conversations rarely progress past the initial greeting.

The refugees, including unaccompanied minors (UM) and rejected claimants who are waiting for the appeal's decision, made their presentations in the meetings. Invariably, they talked about their experience and the problems they faced in preparing for their hearing. The shortcomings-in particular, that they were not given adequate information in preparing their case-have been repeatedly reported. One rejected UM made the pledge, "I have the opportunity to voice the experience here in the meeting because I speak English, but there are thousands who are voiceless and I wish my voice to reflect and echo these voiceless people." The UNHCR representative responded, "for those who don't know refugees, it is certainly moving. For us, nothing new."

Under the CPA, the unaccompanied minors are dealt with by a special committee and the decision for the UM, if their claim is accepted, will be made in their best interest. This applies to other vulnerable groups as well, i.e. women and disabled. Not only has the plan to implement these measures been shelved, adequate counselling to the UM and preparation for the hearing are also almost nonexistent. (Incidentally, processing methods for women and other vulnerable groups by the special committee were listed in/attached to the footnote of the note for UM.)

The issues raised on behalf of UM were:

1. Protection in the Camps. The UM, by and large, have to fend for themselves. A female UM, in particular, has three options to survive in the camps:

i. get married and then have the protection of her husband;

ii. sleep with the 'big brothers' in the camp for protection;

iii.join the gangs.

2. The UM invariably feel confused. They are unhappy about the camp conditions. They feel that they are lost. However, they feel-from their parents or other family members letters-they have an obligation to secure a future for their family. In spite of the information given to the UM by one NGO (NARV - Nordic Assistance to Repatriated Vietnamese) about the improved conditions in Hanoi and Haiphong in North Vietnam, they still have doubts. This is especially clear in the minds of the UM from South Vietnam.

3. Before the CPA, they said the conditions in camps were bad but they know that it is a matter of waiting to be selected for resettlement. After the CPA, uncertainty about the screening and determination process became increasingly intolerable. It seems that their fate is entirely determined by others and beyond their control. For the rejected as well as those accepted, the ultimate decision as to where they will end uprepatriation or resettlement-is made by members of the special committee under the guise of making a decision in the best interest of the children.

4. For the rejected UM, based on information from their parents' letters, returning is not really an option. Their parents advise them to stay put and at times, even said that they did not want them to return. However, no concerted efforts have been made to persuade the parents to encourage the return of these UM. Of course, during the months or years, things might have changed such as remarriage, separation, etc. Generally, the preferred solution, in the best interest of UM, is to send them back to their parents.

5. In some cases, the UM claim is accepted but resettlement is not assured. Based on the special committee's informed decision, the best interest of the UM may be returning home. Also, there are cases where the so-called natural and/or biological parents who are resettled in the West, due to certain changes, may no longer want to receive the
UM. For some UM, growing up with an aunt/ uncle or other relative may not be in their best interest. Only Malaysia, according to the person in charge of the program, admitted that it would take into consideration these variations, keeping in mind that, in all likelihood, returning to natural parents is preferred but not as an exclusive solution. He said that sometimes a quiet approach to parents was made in Vietnam to accept the UM back and at other instances they opt for resettlement of UM with close relatives abroad.

6. Repeatedly, there are calls in the meetings and workshops to give timely and continued counselling to the $\mathrm{UM}$, in addition to providing effective protection to them in camps. However, the need for protection, though acknowledged, has notbeen effectively adressed. While NGOs are faced with limited resources, a UNHCR official stated "They want to go to the West, they don't want to listen to and reason with us."

As the CPA drifts towards its conclusion, hopefully, the mistakes revealed will have a positive impact on the remaining asylum seekers in the camps and their safety and dignity will be protected, not in words but in deeds. w

\section{Notes:}

1. For a comprehensive review of the $C P A$ Colloquium, see Alan Nichols and Paul White, Refugee Dilemmas: Reviewing the Comprehensive Plan of Action for Vietnamese Asylum Seekers, published by LAWASIA Human Rights Committee, 1993.

2. According to the terms of CPA, UNHCR has the authority to use the mandate to give protection to refugees. It was admitted that UNHCR rarely uses this provision so as not to embarrass the host government. One speaker said that the CPA met and exceeded the international standard when compared to the experience in Turkey even though UNHCR has little knowledge on how Turkey determines the refugee status of persons from Europe and there is no international monitoring. 